\title{
Perbandingan Aktivitas Diuretik pada Berbagai Produk Seduhan Teh Hijau (Camellia Sinensis L.)
}

\author{
Agustina Susilowati , Nur Karim Kusuma Ramadhan \\ D3 Farmasi, Akademi Farmasi Indonesia, Yogyakarta, Indonesia \\ *Email: agustinasusilowati@afi.ac.id
}

(Submit 19/12/2021, Revisi 20/12/2021, Diterima 30/12/2021, Terbit 31/12/2021)

\begin{abstract}
Abstrak
Hipertensi merupakan masalah kesehatan yang berbahaya karena memiliki faktor resiko yang mengarah pada penyakit kardiovaskuler. Penggunaan diuretik berperan dalam terapi pengobatan seperti hipertensi, gagal jantung, serta edema. Diketahui bahwa teh hijau dapat berkhasiat sebagai diuretik. Penelitian ini bertujuan mengetahui perbandingan aktivitas diuretik pada berbagai produk teh hijau (Camellia sinensis L.). Pada uji aktivitas diuretik, 30 ekor mencit di bagi menjadi 6 kelompok yang terdiri dari kelompok I (CMC. Na 1\%), Kelompok II (Furosemid), Kelompok III, IV, V dan VI merupakan kelompok perlakuan yang terdiri dari pemberian seduhan White Tea, Yellow Tea, Black Dragon Tea Dan Green Tea Premium dengan dosis $2 \mathrm{~g}, 4 \mathrm{~g}$ dan $6 \mathrm{~g}$ yang diseduh dengan $200 \mathrm{ml}$ air suhu $70^{\circ} \mathrm{C}$ selama 5-15 menit. Pengukuran urin dilakukan setiap 1 jam selama 6 jam. Analisa data dilakukan dengan menggunakan spss versi 26 dengan taraf kepercayaan 95\%. Seduhan white tea, yellow tea, dan black dragon tea pada dosis $2 \mathrm{~g}$ tidak memiliki efek diuretik $(\mathrm{p}>0,05)$ sedangkan green tea premium $2 g$ memiliki aktivitas diuretik namun lebih rendah dibandingkan dengan furosemid. Pada dosis $4 \mathrm{~g}$, white tea, yellow tea dan green tea premium memiliki aktivitas sebagai diuretik $(p<0,05)$ namun masih lebih rendah dibandingkan dengan furosemid. Pada dosis $6 \mathrm{~g}$, white tea, yellow tea, black dragon tea memiliki aktivitas sebagai diuretik $(p<0,05)$ namun masih lebih rendah dibandingkan dengan furosemid, sedangkan green tea premium dosis $6 \mathrm{~g}$ memiliki aktivitas diuretik yang sebanding dengan furosemid $(p>0,05)$. Dapat disimpulkan bahwa white tea, yellow tea, black dragon tea, dan green tea premium dosis $6 \mathrm{~g}$ memiliki aktivitas diuretik.
\end{abstract}

Kata kunci: Aktivitas, Diuretik, Teh Hijau, Seduhan

\section{Pendahuluan}

Hipertensi merupakan masalah kesehatan yang berbahaya karena memiliki faktor resiko yang mengarah pada penyakit kardiovaskuler seperti serangan jantung, gagal jantung, dan stroke, dimana pada tahun 2016 penyakit jantung iskemik dan stroke 
merupakan penyebab utama kematian ${ }^{(1)}$. Prevalensi peningkatan hipertensi di dunia pada orang dewasa berusia 25 tahun ke atas sekitar 40\% pada tahun 2008. Jumlah penderita tekanan darah tinggi yang tidak terkontrol meningkat dari 600 juta pada tahun 1980 menjadi hampir 1 miliar pada tahun $2008^{(2)}$.

Furosemid merupakan obat golongan diuretik yang berperan dalam terapi pengobatan hipertensi(3). Namun, penggunaan furosemid memiliki beberapa efek samping seperti hipokalemia, hiperurisemia dan hiperkalsemia( ${ }^{(4)}$. Kecenderungan masyarakat yang kembali ke alam membawa perubahan pola konsumsi obat kimia terhadap obat-obatan dari alam. Obat tradisional dipilih karena mudah dibuat, harga yang terjangkau dan memiliki efek samping yang rendah(5)(6).

Salah satu tanaman yang dapat memiliki efek diuretik yaitu teh hijau (Camellia sinensis L.). Berdasarkan cara pengolahannya, daun teh hijau memiliki beberapa jenis yaitu white tea, yellow tea, black dragon dan green tea premium. Teh hijau memiliki kandungan senyawa seperti polifenol, tanin, alkaloid, steroid dan flavonoid. Senyawa flavonol dan alkaloid dalam teh hijau dapat menghambat aktivitas ACE. Penghambatan ACE inhibitor tersebut terbukti secara ekperimental dapat memberikan efek diuretik dan bekerja dengan cara meningkatkan ekskresi $\mathrm{Na}^{+}$dan $\mathrm{Cl}^{-}$pada tubulus ${ }^{(7)}$.

Adanya berbagai jenis produk teh hijau tersebut, maka tujuan penelitian ini yaitu mengetahui perbandingan aktivitas diuretik pada berbagai produk teh hijau (Camellia sinensis L.).

\section{Metode}

\section{Alat}

Alat yang digunakan pada penelitian ini adalah kandang mencit, tempat makan dan air minum mencit, wadah penampung urin, kertas saring, corong, beaker glass, sarung tangan, masker, timbangan analitik, kanula (spuit oral), pipet tetes, tabung reaksi dan pengaduk kaca.

\section{Bahan}

Bahan yang digunakan pada penelitian ini adalah simplisia white tea, yellow tea, black dragon tea, green tea premium, furosemid $40 \mathrm{mg}$, CMC Na $1 \%$, aquades, serbuk magnesium, $\mathrm{HCl}$ pekat, $\mathrm{FeCl}_{3} 1 \%$, pereaksi Mayer, Dragendorf, dan Wagner, pakan dan air minum mencit, sekam, dan mencit jantan galur swiss.

\section{Prosedur}

\section{Sampel}

Sampel yang digunakan pada penelitian ini dibeli dari kelompok tani Tegal Subur Nglinggo, Pagerharjo, Samigaluh, Kulon Progo, Yogyakarta. Berikut ini sampel yang digunakan : 
Teh putih (white tea) yang telah memiliki izin pemasaran dengan nomor P-IRT No.5103401080198-19.

Teh kuning (yellow tea) yang telah memiliki izin pemasaran dengan nomor P-IRT No.5103401080198-19.

Teh oolong (black dragon tea) yang telah memiliki izin pemasaran dengan nomor P-IRT No.5103401080198-19.

Green tea premium yang telah memiliki izin pemasaran dengan nomor P-IRT No.5103401080198-19.

\section{Skrining Fitokimia}

Uji Flavonoid : keempat sampel teh ditimbang sebanyak $2 \mathrm{~g}$, masing-masing diseduh dengan $200 \mathrm{ml}$ air panas dengan suhu $70^{\circ} \mathrm{C}$ selama 10 menit. Ambil filtrat secukupnya kemudian tambahkan serbuk magnesium dan beberapa tetes asam klorida pekat. Warna merah atau kuning jingga menunjukkan adanya flavonoid(8).

Uji Saponin : keempat sampel teh ditimbang sebanyak $2 \mathrm{~g}$, masing-masing diseduh dengan $200 \mathrm{ml}$ air panas dengan suhu $70^{\circ} \mathrm{C}$ selama 10 menit. Ambil filtrat dan tambahkan aquadest secukupnya, kemudian kocok kuat selama 10 detik. Adanya saponin ditunjukkan dengan terbentuknya busa yang stabil setinggi $1-3 \mathrm{~cm}^{(8)}$.

Uji Polifenol : keempat sampel teh ditimbang sebanyak $2 \mathrm{~g}$, masing-masing diseduh dengan $200 \mathrm{ml}$ air panas dengan suhu $70^{\circ} \mathrm{C}$ selama 10 menit. Ambil filtrat secukupnya dan tambahkan 1-2 tetes $\mathrm{FeCl}_{3} 1 \%$, jika terjadi warna biru kehitaman atau hijau kehitaman menunjukkan adanya polifenol(8).

Uji Alkaloid : keempat sampel teh ditimbang sebanyak $2 \mathrm{~g}$, masing-masing diseduh dengan $200 \mathrm{ml}$ air panas dengan suhu $70^{\circ} \mathrm{C}$ selama 10 menit. Bagi filtrat menjadi 3 bagian dalam tabung reaksi. Tabung I diberi pereaksi Mayer maka terbentuk endapan putih atau kuning, tabung II diberi pereaksi Dragendorf maka terbentuk endapan coklat atau jingga kecoklatan dan tabung III diberi pereaksi Wagner maka terbentuk endapan coklat kemerahan(8)(9).

\section{Pembuatan Larutan CMC Na 1\%}

CMC Na sebanyak $1 \mathrm{~g}$ ditimbang lalu dikembangkan dalam $20 \mathrm{ml}$ air hangat $\left(60^{\circ} \mathrm{C}\right)$ selama 30 menit. Setelah mengembang, CMC Na digerus sampai homogen, setelah itu ditambahkan aquades sampai $100 \mathrm{ml}^{(10)}$. Volume yang diberikan ke mencit $20 \mathrm{~g}$ adalah $0,2 \mathrm{ml}$.

\section{Pembuatan Suspensi Furosemid}

Dosis furosemid pada manusia adalah $40 \mathrm{mg}$. Dosis tersebut dikonversikan pada mencit $20 \mathrm{~g}$ dengan faktor konversi 0,0026 dan diperoleh dosis furosemid pada mencit sebesar $5,2 \mathrm{mg} / \mathrm{KgBB}$. Pemberian sediaan dilakukan secara per oral dengan volume $1 \%$ dari berat badan hewan uji(11)(12). Volume yang diberikan pada mencit dengan berat badan 
$20 \mathrm{~g}$ adalah $0,2 \mathrm{ml}$. Konsentrasi untuk furosemid dengan dosis $5,2 \mathrm{mg} / \mathrm{KgBB}$ yaitu 0,52 $\mathrm{mg} / \mathrm{ml}$. sebanyak 20 tablet furosemid dengan dosis $40 \mathrm{mg} /$ tablet ditimbang, kemudian dihitung bobot rata-rata setiap tablet. Tablet tersebut dimasukkan ke dalam lumpang dan digerus sampai halus. Sebanyak 22,3405mg serbuk tablet furosemid (setara dengan 5,2 mg furosemid) dilarutkan dengan CMC Na $1 \%$ sampai volume $10 \mathrm{ml}{ }^{(13)}$. Volume suspensi furosemid yang diberikan pada mencit dengan berat $20 \mathrm{~g}$ yaitu $0,2 \mathrm{ml}$.

\section{Pengujian Efek Diuretik Terhadap Mencit Jantan Galur Swiss}

Penelitian ini telah mendapat persetujuan etik dari komite etik penelitian Universitas Ahmad Dahlan dengan nomor 022108035. Sebanyak 30 mencit jantan galur swiss dibagi menjadi 6 kelompok perlakuan, masing-masing perlakuan sebanyak 5 ekor mencit.

Kelompok I (kontrol negatif) : diberi larutan CMC Na $1 \%$ Kelompok II (kontrol positif) : diberi furosemid dosis 5,2 mg/KgBB

Kelompok III (perlakuan) : diberi seduhan teh putih (white tea) yang diseduh dengan $200 \mathrm{ml}$ air suhu $70^{\circ} \mathrm{C}$ selama 5-15 menit.

Kelompok IV (perlakuan) : diberi seduhan teh kuning (yellow tea) yang diseduh dengan $200 \mathrm{ml}$ air suhu $70^{\circ} \mathrm{C}$ selama 5-15 menit.

Kelompok $\mathrm{V}$ (perlakuan) : diberi seduhan teh oolong (black dragon tea) yang diseduh dengan $200 \mathrm{ml}$ air suhu $70^{\circ} \mathrm{C}$ selama 5-15 menit.

Kelompok VI (perlakuan) : diberi seduhan green tea premium yang diseduh dengan $200 \mathrm{ml}$ air suhu $70^{\circ} \mathrm{C}$ selama 5-15 menit.

Mencit diadaptasi selama 7 hari, kemudian dipuasakan selama 12 jam tanpa makan tetapi tetap diberikan air minum dan 2 jam sebelum perlakuan air minum dihentikan. Mencit diberikan air hangat secara per oral sebanyak $0,4 \mathrm{ml} / 20 \mathrm{gBB}^{(14)}$. Volume yang diberikan pada kelompok perlakuan sebanyak $0,2 \mathrm{ml} / 20 \mathrm{gBB}$ mencit. Urin yang di hasilkan ditampung dan diukur volumenya tiap 1 jam selama 6 jam.

\section{Analisa Data}

Data hasil volume urin yang diperoleh kemudian di uji statistika menggunakan SPSS versi 26. Data yang diperoleh dari penelitian di uji normalitas menggunakan uji uji Shapiro Wilk dan uji homogenitas menggunakan uji Levene Test. Pada penelitian ini data terdistribusi normal dan homogen maka data dianalisis menggunakan One-Way Anova dan dilanjutkan uji LSD dengan taraf kepercayaan 95\%.

\section{Hasil}

Hasil dari penelitian ini meliputi hasil uji skrining fitokimia dan hasil uji aktivitas diuretik berbagai produk teh yaitu White tea, Yellow tea, Black dragon tea dan Green tea premium pada dosis $2 \mathrm{~g}$, $4 \mathrm{~g}$ dan $6 \mathrm{~g}$. 
Tabel 1. Hasil Uji Skrining Fitokimia Seduhan Berbagai Produk Teh

\begin{tabular}{lcccc}
\hline \multirow{2}{*}{ Sampel yang Diuji } & \multicolumn{4}{c}{ Hasil Uji Skrining Fitokimia } \\
\cline { 2 - 5 } & Flavonoid & Saponin & Alkaloid & Polifenol \\
\hline White tea & + & + & - & + \\
Yellow tea & + & + & - & + \\
Black dragon tea & + & + & - & + \\
Green tea premium & + & + & - & + \\
\hline
\end{tabular}

Keterangan : + = positif terdapat kandungan senyawa

Tabel 2. Hasil Uji Aktivitas Diuretik Berbagai Produk Teh Dosis $2 \mathrm{~g}$

\begin{tabular}{lccc}
\hline \multicolumn{1}{c}{ Kelompok Perlakuan } & $\begin{array}{c}\text { Rerata } \\
\text { Kumulatif } \\
\text { Volume Urin }\end{array}$ & Aksi Diuretik & $\begin{array}{c}\text { Aktivitas } \\
\text { Diuretik }\end{array}$ \\
\hline Kontrol Negatif & $0,198 \pm 0,189$ & - & - \\
& & & - \\
(CMC Na 1\%) & $1,278 \pm 0,186^{\mathrm{b}}$ & $6,455 \pm 0,372$ & - \\
Kontrol Positif (Furosemide) & $0,434 \pm 0,116^{\mathrm{acd}}$ & $2,192 \pm 0,372$ & $0,339 \pm 0,059$ \\
Seduhan White tea 2g & $0,432 \pm 0,127^{\mathrm{acd}}$ & $2,182 \pm 0,372$ & $0,338 \pm 0,059$ \\
Seduhan Yellow tea 2g & $0,342 \pm 0,130^{\mathrm{acd}}$ & $1,727 \pm 0,372$ & $0,268 \pm 0,059$ \\
Seduhan Black Dragon tea 2g & $0,492 \pm 0,117^{\mathrm{bc}}$ & $2,485 \pm 0,372$ & $0,385 \pm 0,059$ \\
\hline Seduhan Green tea 2g & &
\end{tabular}

Ket. $\mathrm{a}=$ tidak berbeda bermakna dengan kelompok kontrol negatif, $\mathrm{b}=$ berbeda bermakna dengan kelompok kontrol negatif, $c$ = berbeda bermakna dengan kelompok kontrol positif, $d=$ tidak ada perbedaan bermakna antar kelompok pelakuan seduhan berbagai produk teh.

Tabel 3. Hasil Uji Aktivitas Diuretik Berbagai Produk Teh Dosis 4g

\begin{tabular}{lccc}
\hline \multicolumn{1}{c}{ Kelompok Perlakuan } & $\begin{array}{c}\text { Rerata Kumulatif } \\
\text { Volume Urin }\end{array}$ & Aksi Diuretik & $\begin{array}{c}\text { Aktivitas } \\
\text { Diuretik }\end{array}$ \\
\hline Kontrol Negatif & $0,198 \pm 0,189$ & - & - \\
(CMC Na 1\%) & & & - \\
Kontrol Positif (Furosemide) & $1,278 \pm 0,186^{\mathrm{b}}$ & $6,455 \pm 0,423$ & - \\
Seduhan White tea 4g & $0,738 \pm 0,065^{\mathrm{bc}}$ & $3,727 \pm 0,423$ & $0,058 \pm 0,233$ \\
Seduhan Yellow tea 4g & $0,630 \pm 0,535^{\mathrm{bc}}$ & $3,182 \pm 0,423$ & $0,493 \pm 0,233$ \\
Seduhan Black Dragon tea 4g & $0,526 \pm 0,343^{\mathrm{ac}}$ & $2,657 \pm 0,423$ & $0,412 \pm 0,233$ \\
Seduhan Green tea 4g & $0,758 \pm 374^{\mathrm{bc}}$ & $3,828 \pm 0,423$ & $0,593 \pm 0,233$ \\
\hline
\end{tabular}

Ket. $\mathrm{a}=$ tidak berbeda bermakna dengan kelompok kontrol negatif, $\mathrm{b}=$ berbeda bermakna dengan kelompok kontrol negatif $\mathrm{c}=$ berbeda bermakna dengan kelompok kontrol positif 
Tabel 4. Hasil Uji Aktivitas Diuretik Berbagai Produk Teh Dosis 6g

\begin{tabular}{lccc}
\hline \multicolumn{1}{c}{ Kelompok Perlakuan } & $\begin{array}{c}\text { Rerata } \\
\text { Kumulatif } \\
\text { Volume Urin }\end{array}$ & Aksi Diuretik & $\begin{array}{c}\text { Aktivitas } \\
\text { Diuretik }\end{array}$ \\
\hline Kontrol Negatif & $0,198 \pm 0,189$ & - & - \\
(CMC Na 1\%) & & & - \\
Kontrol Positif (Furosemide) & $1,278 \pm 0,185^{\mathrm{a}}$ & $6,455 \pm 0,440$ & - \\
Seduhan White tea 6g & $0,928 \pm 0,100^{\mathrm{ab}}$ & $4,687 \pm 0,440$ & $0,726 \pm 0,089$ \\
Seduhan Yellow tea 6g & $0,818 \pm 0,252^{\mathrm{ab}}$ & $4,131 \pm 0,440$ & $0,640 \pm 0,089$ \\
Seduhan Black Dragon tea 6g & $0,786 \pm 0,478^{\mathrm{ab}}$ & $3,970 \pm 0,440$ & $0,615 \pm 0,089$ \\
Seduhan Green tea 6g & $1,038 \pm 0,663^{\mathrm{ac}}$ & $5,242 \pm 0,440$ & $0,812 \pm 0,089$ \\
\hline
\end{tabular}

Ket. $\mathrm{a}=$ berbeda bermakna dengan kelompok kontrol negatif, $\mathrm{b}=$ berbeda bermakna dengan kelompok kontrol positif, $\mathrm{c}=$ tidak berbeda bermakna dengan kelompok kontrol positif.

\section{Pembahasan}

\section{Hasil Skrining Fitokimia Berbagai Produk The}

Pengujian ini dilakukan untuk mengetahui senyawa yang terkandung dalam seduhan white tea, yellow tea, black dragon tea dan green tea premium. Skrining fitokimia yang dilakukan meliputi uji flavonoid, saponin, uji alkaloid dan uji polifenol. Hasil skrining fitokimia seduhan berbagai produk teh dapat dilihat pada Tabel 1.

Berdasarkan hasil skrining fitokimia seduhan berbagai produk teh pada Tabel 1 menandakan bahwa terdapat kandungan senyawa flavonoid, saponin dan polifenol. Hasil negatif karena komponen pembawa yang digunakan adalah aquadest yang sifatnya polar, sedangkan alkaloid memiliki sifat non polar sehingga senyawa tidak tersari karena tidak larut dalam air ${ }^{15}$. Menurut penelitian yang dilakukan oleh Martono dan Setiyono ${ }^{16}$, bahwa daun teh mengandung senyawa seperti alkaloid, saponin, tanin, polifenol dan flavonoid.

\section{Aktivitas Diuretik pada Berbagai Produk The}

Diuretik dapat menurunkan tekanan darah dengan cara mengurangi cairan dalam tubuh dan juga mengurangi beban kerja jantung, sehingga obat golongan ini berperan penting dalam pengobatan pasien hipertensi ${ }^{17,18}$. Tujuan dari penelitian ini yaitu mengetahui perbandingan aktivitas diuretik pada berbagai produk seduhan teh hijau (Camellia sinensis L.) antara lain white tea, yellow tea, black dragon tea dan green tea premium dalam berbagai dosis. Adapun hasil pengujian aktivitas diuretik pada dosis $2 \mathrm{~g}$ dapat dilihat pada Tabel 2.

Pada Tabel 2 diketahui bahwa seduhan white tea, yellow tea, black dragon tea dan green tea premium pada dosis $2 g$ tidak memiliki efek diuretik $(p>0,05)$ karena tidak berbeda bermakna dibandingkan kelompok kontrol negatif. Sedangkan green tea premium $2 g$ memiliki aktivitas diuretik namun lebih rendah dibandingkan dengan furosemid. Hasil penelitian pada dosis $4 \mathrm{~g}$ dapat dilihat pada Tabel 3. Pada Tabel 3 
diketahui bahwa seduhan white tea, yellow tea, green tea premium $4 \mathrm{~g}$ memiliki efek diuretik $(p<0,05)$ dibandingkan dengan kontrol negatifnya, namun aktivitas diuretiknya masih lebih kecil dibandingkan dengan furosemid. Seduhan black dragon tea pada dosis $4 \mathrm{~g}$ tidak memiliki efek diuretik $(p>0,05)$ karena tidak berbeda bermakna dibandingkan kelompok kontrol negatif.

Perbandingan aktivitas diuretik pada berbagai seduhan produk teh dosis $6 \mathrm{~g}$ dapat dilihat pada Tabel 4. Pada Tabel 4 diketahui seduhan white tea, yellow tea, black dragon tea dan green tea premium pada dosis $6 \mathrm{~g}$ memiliki efek diuretik $(p<0,05)$ karena berbeda bermakna dibandingkan kelompok kontrol negatif. Seduhan white tea, yellow tea, dan black dragon tea dosis $6 \mathrm{~g}$ memiliki aktivitas diuretik $(p<0,05)$ namun lebih kecil dibandingkan dengan furosemid. Sedangkan untuk seduhan green tea premium $6 \mathrm{~g}$ memiliki aktivitas diuretik yang tidak berbeda bermakna $(p>0,05)$ dengan furosemid.

Efek diuretik dari seduhan white tea disebabkan karena adanya kandungan senyawa flavonoid. Mekanisme kerja dari flavonoid sebagai diuretik yaitu menghambat reabsorbsi $\mathrm{Na}^{+}, \mathrm{K}^{+}$dan $\mathrm{Cl}^{-}$yang menyebabkan peningkatan elektrolit ${ }^{19}$. Seduhan yellow tea memiliki efek diuretik karena adanya senyawa flavonoid. Menurut Anna ${ }^{20}$ flavonoid merupakan senyawa yang mempunyai aktivitas biologis sebagai diuretik. Flavonoid bekerja dengan mekanisme peningkatan ekskresi elektrolit seperti $\mathrm{Na}^{+}$dan $\mathrm{Cl}^{-}$pada tubulus sehingga menimbulkan efek diuretik ${ }^{21}$. Hasil tersebut sesuai dengan penelitain Susilowati ${ }^{7}$ bahwa teh hijau memiliki efek diuretik. Selain flavonoid didalam teh juga terkandung senyawa saponin. Menurut Sari22, saponin adalah senyawa yang memiliki sifat menurunkan tegangan permukaan sehingga dapat merangsang ginjal untuk bekerja lebih aktif dan juga dapat absorbsi diuretik, terutama yang terbentuk garam didalam urin.

\section{Kesimpulan}

Pada penelitian ini dapat disimpulkan bahwa seduhan white tea, yellow tea, black dragon dosis $2 \mathrm{~g}$ tidak memiliki aktivitas diuretik sedangkan green tea premium $2 \mathrm{~g}$ memiliki aktivitas diuretik namun lebih rendah dibandingkan dengan furosemid. Seduhan white tea, yellow tea dan green tea premium dosis $4 \mathrm{~g}$ memiliki aktivitas diuretik namun lebih kecil dibandingkan furosemid. Seduhan white tea, yellow tea, black dragon tea dosis $6 g$ memiliki aktivitas diuretik namun lebih kecil dibandingkan furosemid. Seduhan green tea premium $6 \mathrm{~g}$ memiliki aktivitas diuretik yang setara dengan furosemid.

\section{Daftar Pustaka}

1. WHO. 2018. Global Health Estimates 2016: Deaths by Cause, Age, Sex, by Country and by Region, 2000-2016. Geneva: World Health Organization.

2. WHO. 2013, A global brief on Hypertension: silent killer, global public health crises (World Health Day 2013), Geneva: WHO.

3. Snigdha M., Kumar S.S., Jaya Y. and Kasana B., 2013, Review Article a Review on "How Exactly Diuretic Drugs Are Working in Our Body". Journal of Drug Delivery \& Therapeutics. 3 (5): 115-120. 
4. Nafrialdi, G., \& Sulistia, G. (2011). Farmakologi dan Terapi Edisi 5 Cetakan Ulang Dengan Tambahan. Jakarta: Universitas Indonesia.

5. Sariana. 2011. Uji Efek Analgetik Dari Infusa Daun Asam Jawa (Tamarindus indica Linn) Pada Mencit (Mus muskulus). Skripsi. Makassar : Universit.as Islam Negeri Alauddin.

6. Winarti., L dan Wantiyah. 2011. Uji Efek Analgetik Ekstrak Rimpang Temu Kunci (Boesenbergia pandurata Roxb) Schlechter Pada Mencit Jantan Galur Swiss. Majalah Obat Tradisional. 16(1): 26-33.

7. Susilowati, Agustina. 2019. Diuretic Effect Of The Aqueous Extract Of Green Tea Leaves. Advances in Health Science Research. 15: 33-36.

8. Anggreni, T,U., 2020. Penetapan Aktivitas Antioksidan dengan Metode Total Fenol Dan Total Flavonoid Dari Seduhan Teh Putih (Camellia sinensis (L.) Kuntze). Skripsi. Medan: Fakultas Farmasi Universitas Sumatera Utara.

9. Yanti, S dan Vera, Y., 2019. Skrining Fitokimia Ekstrak Daun Belimbing Wuluh (Averrhoa bilimbi). Jurnal Kesehatan IImiah Indonesia. 4(2): 41-46.

10. Marlyne, I,S., Citraningtyas, G., dan Lolo, W,A., 2012. Uji Efek Analgetik Ekstrak Etanol 70\% Bunga Mawar (Rosa chinesis Jacq.) Pada Mencit Yang Diinduksi Asam Asetat. Skripsi. Depok: FMIPA Universitas Indonesia.

11. Syamsudin, \& Darmono. (2011). Buku Ajar : Farmakologi Eksperimental. Jakarta: Penerbit UI. Hal : 8,21.

12. Nessa., Arifin, H., dan Muchtar, H., 2013. Efek Diuretik Dan Daya Larut Batu Ginjal Dari Ektrak Etanol Rambut Jagung (Zea mays L.). Prosiding Seminar Nasional Perkembangan Terkini Sains Farmasi Klinik III. 345-358.

13. Herman, H., Azizah, R.N., dan Inaku, C., 2012. Uji Efek Diuretik Infus Biji Jagung (Zea mays L.), Rambut Jagung Dan Kombinasi Antar Keduanya Pada Kelinci Jantan (Oryctolagus cuniculus) Berdasarkan Parameter Frekuensi Urinasi Dan Volume Urin. As-Syifa. 04(01): 65-73.

14. Purwidyaningrum, I., Sukandar, E,Y., dan Fidrianny. 2016. Diuretic Activity Of Differens Organs Of Matoa (Pometia pinnata) Ekstracts And Its Influence On Potassium And Sodium Levels. International Journal Of Pharmacognosy And Phytochemical Research. 8(2): 244-247.

15. Sumiati, T., Ferry, E., dan Muhamad, S.I., 2016. Potensi Ekstrak Daun Alpukat (Persea americana M.) Sebagai Diuretik Pada Tikus Putih Jantan. Jurnal Farmamedika. 1(1): 19-27.

16. Martono, Budi dan Setiyono, R.T., 2014. Skrining Fitokimia Enam Genotipe Teh. J.TIDP. 1(2): 63-68. 
17. Muthia, R., Amalia., Ahmad, M., Maulidya, R.P., Gusti, R., dan Selva, A., 2017. Uji Aktivitas In Vivo Ekstrak Etanol Kulit Buah Semangka (Citrulus Lanatus L.) Sebagai Diuretik Dengan Pembanding Furosemid. Jurnal Borneo Journal of Pharmascientech. 1(1): 67-75.

18. Susilo, Y., Wulandari, A.. 2011. Cara Jitu Mengatasi Hipertensi. Yogyakarta: Penerbit Andi.

19. Deswati, D.A., Dadan, R., dan Sari, A. 2020. Uji Efek Diuretik Seduhan white tea (Camellia sinensis L.) Pada Mencit Putih Jantan Galur Swiss Webster. Jurnal Sabdariffarma. 6(1): 25-32.

20. Anna., 2011. Uji Efek Diuretik Ekstrak Etanol 70\% Daun Ceplukan (Physalis angulata $L)$. Surakarta: Universitas Muhammadiyah Surakarta.

21. Arnasaputra., 2011. Uji Dosis Ekstrak Etanol Kelompok Bunga Rosella (Hibiscus sabsarifa L.) Sebagai Diuretik Pada Tikus Putih Jantan (Rattus novergicus). In: Skripsi. Surakarta: Universitas Sebelas Maret.

22. Sari, Rika Puspita., 2020. Efek Diuretik Ekstrak Etanol Rimpang Temu Hitam (Curcuma aeruginosa Roxb) Pada Tikus Putih Jantan. Jurnal Dunia Farmasi. Volume 5(1): 40-45. 